The University of New South Wales Australian School of Business

School of Economics Discussion Paper: 2010/01

\title{
Tobit or OLS? An Empirical Evaluation under Different Diary Window Lengths
}

Gigi Foster and Charlene M. Kalenkoski

School of Economics

Australian School of Business

UNSW Sydney NSW 2052 Australia

http://www.economics.unsw.edu.au

ISSN 1837-1035

ISBN $978073342856-2$ 


\title{
Tobit or OLS? An empirical evaluation under different diary window lengths
}

\author{
Gigi Foster and Charlene M. Kalenkoski
}

\author{
Gigi Foster \\ University of New South Wales \\ School of Economics \\ Level 4, Building E12 - ASB \\ Sydney, NSW 2052 \\ gigi.foster@unsw.edu.au \\ Charlene M. Kalenkoski \\ Ohio University \\ Department of Economics \\ Bentley Annex 351 \\ Athens, $\mathrm{OH} 45701$ \\ kalenkos@ohio.edu (for correspondence)
}

January 5, 2010

\begin{abstract}
Time use researchers frequently debate whether it is more appropriate to fit censored regression (Tobit) models using maximum likelihood estimation or linear models using ordinary least squares (OLS) to explain individuals' allocations of time to different activities as recorded in time-diary data. One side argues that estimation of Tobit models addresses the significant censoring (i.e., large numbers of zeros) typically found in time-diary data and that OLS estimation leads to biased and inconsistent estimates. The opposing side argues that optimization occurs over a longer period than that covered by the typical time diary, and thus that reported zeros represent measurement error rather than true non-participation in the activity, in which case OLS is preferred. We use the Australian Time Use Surveys, which record information for two consecutive diary days, to estimate censored and linear versions of a parental child care model for both 24-hour and 48-hour windows of observation in order to determine the empirical consequences of estimation technique and diary length. We find a moderate amount of measurement error when we use the 24-hour window compared to the 48-hour window, but a large number of zeros in the shorter window remain zeroes when we double the window length. Most of the qualitative conclusions we draw are similar for the two windows of observation and the two estimation methods, although there are some slight differences in the magnitudes and statistical significance of the estimates. Importantly, Tobit estimates appear to be more sensitive to window length than OLS estimates.
\end{abstract}




\section{Foster/Kalenkoski}

JEL Key words: Quantitative Methods

Own keywords: Tobit, OLS, time-diary data 


\section{Introduction}

Time use researchers have debated whether it is more appropriate to estimate censored regression (Tobit) models via maximum likelihood or linear models using ordinary least squares (OLS) to analyze the determinants of time spent in a particular activity, e.g. child care, when using time-diary data of limited duration. Proponents argue that Tobit models address the significant censoring (i.e., large numbers of zeros) typically found in these data and that, because linear models ignore this censoring, OLS estimation leads to biased and inconsistent estimates (see Greene 1997 for a discussion of how OLS coefficients are biased and inconsistent in the presence of censoring). This has led to widespread use of Tobit models of parents' child care time, especially among economists (see, for example, Floro and Miles (2003), Kalenkoski, Ribar, and Stratton (2005, 2007, and 2009), Kimmel and Connelly (2007), and Kalenkoski and Foster (2008)). Yet, because Tobit models treat a record of zero time for a particular activity in a time diary as non-participation in the activity, some individuals who regularly engage in an activity but do not do so during the limited time period covered by the time diary may be misidentified as non-participators. Because these zeros represent measurement error rather than nonparticipation, some suggest that OLS should be used (Stewart 2009, Gershuny and Egerton 2007). However, a careful empirical comparison of estimation results obtained using OLS and Tobit has not yet been published. ${ }^{1}$

In this paper we investigate the extent of measurement error in measuring parental child care time, a relatively frequent and often analyzed activity, and one for which OLS has been proposed as an alternative to Tobit. We are able to assess the extent of measurement error due to a specific feature of our data. We use the Australian Time Use Surveys, which provide time-diary information for 48 hours (two consecutive diary days) for each individual respondent. Thus, we are able to compare the apparent frequency of non-participation when we use the 24-hour window with the frequency of non-participation when we use the 48-hour window to determine the percent of "false zeros" that one obtains when only one diary day is available (e.g., as in the American Time Use Survey (ATUS)).

We then compare the OLS and Tobit results for the two diary window lengths. Specifically, we compare OLS-fitted linear child care time equations across the two window lengths; Tobit child care equations across the two window lengths; and OLS coefficients and Tobit marginal effects within each of the two window lengths. All estimation is performed for mothers and fathers separately because it is well-known that caregiving time differs by gender. In addition, because decisions regarding parental child care time may be made weekly rather than daily, and because mothers and fathers may substitute their time so that mothers spend more time in child care on weekdays and fathers spend more time on weekends, we make several different comparisons of the one-day versus two-day results depending on the types of days that are available. We separately examine a two-weekday diary (i.e, we compare minutes spent in a 24-hour weekday with the average daily minutes spent in a 48hour period with two weekdays); a two-weekend-day diary (i.e., we compare minutes

\footnotetext{
${ }^{1}$ In their unpublished paper, Gershuny and Egerton (2007) engage in a comparison of Tobit and OLS estimation but incorrectly compare OLS coefficients to Tobit coefficients rather than marginal effects. Stewart's (2009) working paper provides useful comparative simulations for Tobit and OLS, but does not apply different estimation methods to real data.
} 


\section{Foster/Kalenkoski}

spent in a 24-hour weekend day with the average daily minutes spent in a 48-hour period with two weekend days); and a both-day-type diary (i.e., we compare daily minutes for a 24-hour weekday or weekend day (randomly chosen) with the average daily minutes spent in a 48-hour period that includes both a weekday and a weekend day). Although there are a few existing time use surveys that provide information for more than two days, most have only one or two days of information. Therefore, our comparison of one-day diaries to two-day diaries provides some suggestive evidence regarding the extent to which having two days of information is indeed better than having one.

We find that our qualitative conclusions are the same regardless of the window or method used, although there are some slight differences in the magnitudes and statistical significance of the estimates. However, Tobit estimates appear to be more sensitive to window length than OLS estimates.

\section{Data}

Our data are drawn from the 1992 and 1997 Australian Time Use Surveys. Each survey contains two consecutive days' worth of time-diary data on all adults in a random sample of Australian households. Given the consecutive nature of the two diary days, we treat them together as one 48-hour (2880 minute) reporting period. Our starting data set therefore includes one observation per individual on an array of household-specific and person-specific variables, including the amount of time an individual spent on child care as a primary activity during the 48-hour window.

Because we wish to compare results based on one diary day with those based on two diary days, we exclude from our sample the few individuals who reported time use for only one day. We also exclude households without children, as they are unlikely to be providing child care, and those in which an adult is studying full-time, parttime, or by correspondence, as students are likely to exhibit different time use patterns than non-students. Our final analysis sample includes 3,791 men and 4,481 women.

The dependent variable in the models we estimate is daily minutes spent by a parent in child care as a primary activity. We obtain this measure in two different ways. First, we randomly select one day out of the two consecutive diary days for which we have data, for each person in our sample, to mimic what would happen if we only had a 24-hour time diary. Minutes spent in child care as a primary activity on this diary day serves as the dependent variable for estimations that utilize a 24-hour window of observation. To obtain a comparable measure of average daily minutes spent in child care utilizing the full 48 -hour window of observation, we divide the number of minutes spent in the full 48 -hour period by two.

We employ maximum likelihood techniques to estimate Tobit models and OLS regression to estimate linear models on the full complement of day-type and window-length combinations. Our analysis subsamples thus include one 24-hour weekday; a 48-hour period consisting of two weekdays; one 24-hour weekend day; a 48-hour period consisting of two weekend days; one 24-hour period consisting of both weekdays and weekend days (a weekday for some observations and a weekend day for others); and a 48-hour period consisting of one weekday and one weekend 
day per observation. Each observation falls into one day-type group (two weekdays, two weekend days, or both day types). Table 1 provides descriptive statistics for the dependent variable used in the analysis, broken down by gender and day-type subsample.

\section{Table 1: $\quad$ Descriptive Statistics}

\begin{tabular}{|c|c|c|c|}
\hline & \multicolumn{3}{|c|}{ Men } \\
\hline & Both Day Types & Two Weekdays & Two Weekend Days \\
\hline Primary child care (48h window) & $\begin{array}{c}33.53 \\
(56.66)\end{array}$ & $\begin{array}{c}31.58 \\
(53.12)\end{array}$ & $\begin{array}{c}39.72 \\
(67.86)\end{array}$ \\
\hline Primary child care (24h window) & $\begin{array}{c}33.04 \\
(63.69)\end{array}$ & $\begin{array}{c}30.62 \\
(57.48)\end{array}$ & $\begin{array}{l}41.26 \\
(79.77)\end{array}$ \\
\hline $\mathbf{N}$ & 2218 & 1281 & 292 \\
\hline & Both Day Types & $\begin{array}{c}\text { Women } \\
\text { Two Weekdays }\end{array}$ & Two Weekend Days \\
\hline Primary child care (48h window) & $\begin{array}{c}102.55 \\
(120.11)\end{array}$ & $\begin{array}{c}109.79 \\
(124.08)\end{array}$ & $\begin{array}{c}86.85 \\
(111.54)\end{array}$ \\
\hline Primary child care (24h window) & $\begin{array}{c}103.01 \\
(128.32)\end{array}$ & $\begin{array}{c}109.16 \\
(130.24)\end{array}$ & $\begin{array}{c}84.39 \\
(123.43)\end{array}$ \\
\hline $\mathbf{N}$ & 2615 & 1512 & 354 \\
\hline
\end{tabular}

Explanatory variables in our parental child care time use models include indicators for whether or not the respondent is single; speaks a language other than English in the home; is Australian; is in a certain age range; lives in a non-metropolitan urban area or a rural area; works in a particular industry or occupational group; provides no occupation or industry information; and has attained various levels of education. We also include indicators for whether the household contains disabled children or adults; whether there are other adults in the household besides the respondent and a spouse or partner; the number and youngest age of dependent children living in the household; the number of people in different age ranges living in the household; the number of women in the household; household structure; whether anyone in the household reported that child care was difficult to find; and survey year (1992 or 1997). ${ }^{2}$

\section{$3 \quad$ Models}

Our dependent variable is actual daily minutes spent in primary child care if we are using a 24-hour window and average daily minutes spent in primary child care if we are using a 48-hour window. Thus, our dependent variable is always bounded between 0 and 1440 - the number of minutes in a 24-hour period.

The linear models we estimate using OLS are of the form:

\footnotetext{
${ }^{2} \mathrm{An}$ indicator for weekend is also included in the 24-hour models that include a weekend day and a weekday.
} 
(1) $Y=\beta_{0}+x \beta_{1}+u$

where $\mathrm{Y}$ is the observed time spent in child care, $\mathrm{x}$ is the vector of measured personal and household characteristics that explain variation in $\mathrm{Y}, \beta_{0}$ and $\beta_{1}$ are parameters to be estimated, and $u$ is a normally distributed error term with mean zero and variance $\sigma^{2}$.

The models we estimate via maximum likelihood that control for both left- and rightcensoring are of the form:

(2) $\mathrm{Y}^{*}=\beta_{0}+\mathrm{x} \beta_{1}+\mathrm{u}$

$$
\begin{aligned}
& \mathrm{Y}=\mathrm{Y}^{*} \text { if } 1440>\mathrm{Y}^{*}>0 \\
& \mathrm{Y}=0 \text { if } \mathrm{Y}^{*} \leq 0 \\
& \mathrm{Y}=1440 \text { if } \mathrm{Y}^{*} \geq 1440
\end{aligned}
$$

where $\mathrm{Y}^{*}$ is a latent variable representing desired hours of child care time, which can be negative for a person with a great dislike for performing child care or greater than the total minutes available in a day for a person who derives a great deal of utility from child care.

\section{$4 \quad$ Results}

We begin by presenting information related to the extent of the "false zeroes" present in our data set. We define a "false zero" as an instance where a respondent reports zero minutes of child care time in the 24-hour window, but positive minutes of child care time in the corresponding 48-hour window. Table 2 presents the percentages of false zeroes in our samples, where the numerator in each calculation is the number of false zeroes and the denominator varies by column. In the first column the denominator is simply the sample size. In the second column the denominator is the number of individuals reporting positive minutes in a 48-hour window. Finally, in the third column the denominator is the number of zeros when using the 24-hour window only. The percentages get larger as we move across the columns. The third column is the most interesting, as it represents the degree to which we "get it wrong" if we use only the 24-hour period. This is largest for the sample for which we have both a weekday and a weekend day, which is expected if we think that time allocation occurs over the course of a week and is quite different on weekdays and weekends. Note, however, that while the largest percentage of false zeros in any row is just over $17 \%$, this implies that the percentage of "correct zeroes" is $83 \%$, suggesting that true non-participation explains more zeroes than measurement error. Hence, a Tobit model or another model that accounts for such non-participation may be warranted. (Overall, those reporting zero minutes of child care in our sample represent from $35 \%$ to $43 \%$ of the observations, depending on day type and window length.) 
Table 2: $\quad$ False zeroes

\section{PRIMARY CHILD CARE}

Both Day Types

Two Weekdays

Two Weekend Days

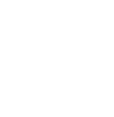

$\mathrm{N}$

4833

2793

646
False zeroes: Percent False zeroes: Percent of those reporting of those reporting

False zeroes: Percent positive minutes in 48- zero minutes in 24of sample hour window hour window

$17.07 \%$

$15.77 \%$

$15.95 \%$

We now turn to selected results from our estimated child care equations. ${ }^{3}$ Tables 3-8 present results for the various gender-day-type samples. All tables show OLS coefficients and standard errors and Tobit marginal effects and standard errors. ${ }^{4}$ In all tables, three stars next to an estimate denotes statistical significance at the $1 \%$ level; two stars, significance at the $5 \%$ level; and one star, significance at the $10 \%$ level.

\section{Table 3: $\quad$ Men, Both Day Types}

\begin{tabular}{|c|c|c|c|c|}
\hline \multirow{3}{*}{ Dependent Variables } & \multicolumn{4}{|c|}{ Window lengths } \\
\hline & \multicolumn{2}{|c|}{ 24-hour } & \multicolumn{2}{|c|}{ 48-hour } \\
\hline & OLS & Tobit & OLS & Tobit \\
\hline \multicolumn{5}{|l|}{ Selected Person-level Explanatory Variables } \\
\hline Single & $-29.11^{* * *}(7.58)$ & $-28.86^{* * *}(3.41)$ & $-27.23^{* * *}(6.56)$ & $-28.94^{* * *}(3.24)$ \\
\hline Speaks language other than English at home & $-3.12(4.82)$ & $-1.52(3.34)$ & $-1.96(4.18)$ & $-1.17(3.11)$ \\
\hline Bachelors degree or higher & $15.64^{* * *}(4.94)$ & $11.99^{* * *}(3.81)$ & $12.52^{* * *}(4.28)$ & $10.20^{* * *}(3.42)$ \\
\hline Indicator for other adults (age 15+) in the household & $-23.22^{* * *}(6.74)$ & $-22.04^{* * *}(4.80)$ & $-26.15^{* * *}(5.83)$ & $-23.74^{* * *}(4.34)$ \\
\hline Age of youngest child in household is 2 to 4 years & $-6.88^{*}(4.02)$ & $-2.40(3.11)$ & $-6.57^{*}(3.48)$ & $-1.92(2.80)$ \\
\hline Age of youngest child in household is 5 to 9 years & $-22.48^{* * *}(4.14)$ & $-11.39^{* * *}(3.02)$ & $-22.75^{* * *}(3.58)$ & $-11.26^{* * *}(2.71)$ \\
\hline Age of youngest child in household is greater than 9 years & $-28.63^{* * *}(4.41)$ & $-18.63^{* * *}(3.07)$ & $-26.46^{* * *}(3.82)$ & $-16.02^{* * *}(2.86)$ \\
\hline Non-metropolitan urban area & $0.06(2.97)$ & $.45(2.13)$ & $-2.44(2.57)$ & $-1.69(1.95)$ \\
\hline Rural area & $-3.37(4.07)$ & $-2.39(2.73)$ & $-4.26(3.52)$ & $-3.34(2.53)$ \\
\hline Household has three dependent children & $5.92(3.88)$ & $4.10(2.53)$ & $3.15(3.36)$ & $1.20(2.35)$ \\
\hline Household has four or more dependent children & $15.10^{* * *}(4.51)$ & $13.73^{* * *}(3.85)$ & $10.99^{* * *}(3.91)$ & $9.25^{* * *}(3.40)$ \\
\hline
\end{tabular}

\footnotetext{
${ }^{3}$ Results for the full set of explanatory variables are available upon request.

${ }^{4}$ For the censored Tobit models, all marginal effects are calculated in comparison to the omitted category for the relevant dummy array. With respect to the selected results shown in these tables, the omitted categories are: married, speaking English at home, has not completed high school, no other adults in the household, age of youngest child in household is less than 2 years, household located in a metropolitan urban area, and household has one dependent child.
} 


\section{Foster/Kalenkoski}

Table 4: $\quad$ Women, Both Day Types

\begin{tabular}{|c|c|c|c|c|}
\hline \multirow{3}{*}{ Dependent Variables } & \multicolumn{4}{|c|}{ Window lengths } \\
\hline & \multicolumn{2}{|c|}{ 24-hour } & \multicolumn{2}{|c|}{ 48-hour } \\
\hline & OLS & Tobit & OLS & Tobit \\
\hline \multicolumn{5}{|l|}{ Selected Person-level Explanatory Variables } \\
\hline Single & $-26.65^{* * *}(8.94)$ & $-40.89^{* * *}(8.04)$ & $-24.71^{* * *}(7.98)$ & $-36.30^{* * *}(7.45)$ \\
\hline Speaks language other than English at home & $-18.24^{* *}(7.66)$ & $-15.77^{* *}(6.73)$ & $-22.12^{* * *}(6.84)$ & $-20.21^{* * *}(6.07)$ \\
\hline Bachelors degree or higher & $38.77^{* * *}(8.45)$ & $36.79^{* * *}(8.49)$ & $41.21^{* * *}(7.54)$ & $39.20^{* * *}(7.76)$ \\
\hline Indicator for other adults (age 15+) in the household & $-70.85^{* * *}(9.90)$ & $-83.10^{* * *}(8.35)$ & $-81.23^{* * *}(8.83)$ & $-91.41^{* * *}(7.43)$ \\
\hline Age of youngest child in household is 2 to 4 years & $-70.34^{* * *}(6.09)$ & $-50.12^{* * *}(6.06)$ & $-68.72^{* * *}(5.43)$ & $-52.19^{* * *}(5.46)$ \\
\hline Age of youngest child in household is 5 to 9 years & $-106.32^{* * *}(6.29)$ & $-73.00^{* * *}(6.05)$ & $-100.78^{* * *}(5.62)$ & $-72.65^{* * *}(5.47)$ \\
\hline Age of youngest child in household is greater than 9 years & $-117.24^{* * *}(6.94)$ & $-89.73^{* * * *}(6.33)$ & $-111.67^{* * *}(6.19)$ & $-86.73^{* * *}(5.79)$ \\
\hline Non-metropolitan urban area & $-11.76^{* * *}(4.55)$ & $-11.26^{* * *}(4.21)$ & $-10.70^{* * *}(4.06)$ & $-9.62^{* *}(3.88)$ \\
\hline Rural area & $-10.26(6.37)$ & $-11.30^{*}(5.80)$ & $-7.01(5.68)$ & $-7.95(5.41)$ \\
\hline Household has two dependent children & $-1.25(4.98)$ & $-1.16(4.46)$ & $.58(4.44)$ & $-.66(4.14)$ \\
\hline Household has four or more dependent children & $5.73(7.05)$ & $6.26(6.89)$ & $5.64(6.29)$ & $3.91(6.26)$ \\
\hline
\end{tabular}

\section{Table 5: $\quad$ Men, Two Weekdays}

\begin{tabular}{|c|c|c|c|c|}
\hline \multirow{3}{*}{ Dependent Variables } & \multicolumn{4}{|c|}{ Window lengths } \\
\hline & \multicolumn{2}{|c|}{ 24-hour } & \multicolumn{2}{|c|}{ 48-hour } \\
\hline & OLS & Tobit & OLS & Tobit \\
\hline \multicolumn{5}{|l|}{ Selected Person-level Explanatory Variables } \\
\hline Single & $-21.70^{* *}(8.73)$ & $-21.35(26.40)$ & $-25.60^{* * *}(7.84)$ & $-27.62^{* * *}(3.78)$ \\
\hline Speaks language other than English at home & $2.14(5.98)$ & $2.51(5.19)$ & $1.72(5.37)$ & $1.99(4.24)$ \\
\hline Bachelors degree or higher & $9.18(6.07)$ & $9.98(11.85)$ & $4.15(5.45)$ & $6.80^{*}(4.07)$ \\
\hline \multicolumn{5}{|l|}{ Selected Household-level Explanatory Variables } \\
\hline Indicator for other adults (age 15+) in the household & $-27.69^{* * *}(7.81)$ & $-24.49(27.43)$ & $-27.02^{* * *}(7.02)$ & $-25.96^{* * *}(5.13)$ \\
\hline Age of youngest child in household is 2 to 4 years & $-15.75^{* * *}(4.73)$ & $-6.89(7.64)$ & $-12.18^{* * *}(4.25)$ & $-4.75(3.28)$ \\
\hline Age of youngest child in household is 5 to 9 years & $-27.73^{* * *}(5.03)$ & $-12.64(13.88)$ & $-25.22^{* * *}(4.52)$ & $-12.09^{* * *}(3.29)$ \\
\hline Age of youngest child in household is greater than 9 years & $-28.21^{* * *}(5.33)$ & $-13.91(15.52)$ & $-26.66^{* * *}(4.79)$ & $-13.48^{* * *}(3.67)$ \\
\hline Non-metropolitan urban area & $1.24(3.57)$ & $1.30(2.85)$ & $1.96(3.21)$ & $1.53(2.47)$ \\
\hline Rural area & $4.24(4.96)$ & $1.76(3.98)$ & $-.59(4.46)$ & $-.66(3.26)$ \\
\hline Household has three dependent children & $8.91^{*}(4.68)$ & $3.06(4.62)$ & $4.88(4.20)$ & $1.89(2.94)$ \\
\hline Household has four or more dependent children & $10.99^{* *}(5.43)$ & $7.67(9.34)$ & $8.65^{*}(4.87)$ & $7.34^{*}(3.99)$ \\
\hline
\end{tabular}


Table 6: Women, Two Weekdays

\begin{tabular}{|c|c|c|c|c|}
\hline \multirow{3}{*}{ Dependent Variables } & \multicolumn{4}{|c|}{ Window lengths } \\
\hline & \multicolumn{2}{|c|}{ 24-hour } & \multicolumn{2}{|c|}{ 48-hour } \\
\hline & OLS & Tobit & OLS & Tobit \\
\hline \multicolumn{5}{|l|}{ Selected Person-level Explanatory Variables } \\
\hline Single & $-20.96^{*}(11.39)$ & $-34.47^{* * *}(10.74)$ & $-23.90^{* *}(10.30)$ & $-37.38^{* * *}(9.87)$ \\
\hline Speaks language other than English at home & $-27.33^{* * *}(10.45)$ & $-21.84^{* *}(9.08)$ & $-24.87^{* * *}(9.45)$ & $-20.39^{* *}(8.64)$ \\
\hline Bachelors degree or higher & $36.84^{* * *}(11.25)$ & $35.59^{* * *}(11.31)$ & $40.68^{* * *}(10.17)$ & $38.48^{* * *}(10.50)$ \\
\hline \multicolumn{5}{|l|}{ Selected Household-level Explanatory Variables } \\
\hline Indicator for other adults (age 15+) in the household & $-93.16^{* * *}(13.05)$ & $-106.67^{* * *}(10.52)$ & $-84.68^{* * *}(11.80)$ & $-98.48^{* * *}(9.99)$ \\
\hline Age of youngest child in household is 2 to 4 years & $-58.55^{* * *}(8.02)$ & $-39.58^{* * *}(7.85)$ & $-64.84^{* * *}(7.25)$ & $-48.26^{* * *}(7.26)$ \\
\hline Age of youngest child in household is 5 to 9 years & $-92.04^{* * *}(8.49)$ & $-60.99^{* * *}(8.00)$ & $-97.03^{* * *}(7.68)$ & $-69.38^{* * *}(7.39)$ \\
\hline Age of youngest child in household is greater than 9 years & $-100.46^{* * *}(9.45)$ & $-73.77^{* * *}(8.63)$ & $-104.89^{* * *}(8.54)$ & $-78.13^{* * *}(8.06)$ \\
\hline Non-metropolitan urban area & $-19.70^{* * *}(6.03)$ & $-12.47^{* * *}(8.13)$ & $-18.94^{* * *}(5.45)$ & $-17.97^{* * *}(5.20)$ \\
\hline Rural area & $-10.26(8.71)$ & $-12.47(8.13)$ & $-5.55(7.88)$ & $-7.77(7.70)$ \\
\hline Household has two dependent children & $9.78(6.64)$ & $6.43(6.60)$ & $6.32(6.01)$ & $4.32(5.63)$ \\
\hline Household has four or more dependent children & $12.81(9.31)$ & $15.38^{*}(9.11)$ & $11.17(8.42)$ & $11.61(8.42)$ \\
\hline
\end{tabular}

Table 7: $\quad$ Men, Two Weekend Days

\begin{tabular}{|c|c|c|c|c|}
\hline \multirow{3}{*}{ Dependent Variables } & \multicolumn{4}{|c|}{ Window lengths } \\
\hline & \multicolumn{2}{|c|}{ 24-hour } & \multicolumn{2}{|c|}{ 48-hour } \\
\hline & OLS & Tobit & OLS & Tobit \\
\hline \multicolumn{5}{|l|}{ Selected Person-level Explanatory Variables } \\
\hline Single & $-28.94(29.91)$ & $-2.75(51.35)$ & $-26.61(25.32)$ & $-21.36(66.19)$ \\
\hline Speaks language other than English at home & $-7.92(17.43)$ & $0.44(8.15)$ & $9.83(14.75)$ & $13.52(33.88)$ \\
\hline Bachelors degree or higher & $39.55^{* *}(15.56)$ & $2.93(47.58)$ & $24.44^{*}(13.17)$ & $10.37(23.63)$ \\
\hline \multicolumn{5}{|l|}{ Selected Household-level Explanatory Variables } \\
\hline Indicator for other adults (age 15+) in the household & $-54.04^{* *}(24.83)$ & $-3.19(57.00)$ & $-31.03(21.01)$ & $-10.35(30.78)$ \\
\hline Age of youngest child in household is 2 to 4 years & $-38.28^{* * *}(14.58)$ & $-4.55(66.25)$ & $-29.75^{* *}(12.34)$ & $-17.85(34.79)$ \\
\hline Age of youngest child in household is 5 to 9 years & $-65.23^{* * *}(14.77)$ & $-6.14(95.02)$ & $-49.05^{* * *}(12.50)$ & $-24.88(52.21)$ \\
\hline Age of youngest child in household is greater than 9 years & $-80.74^{* * *}(15.91)$ & $-6.63(105.74)$ & $-63.37^{* * *}(13.47)$ & $-35.79(88.62)$ \\
\hline Non-metropolitan urban area & $-25.96^{* *}(10.58)$ & $-0.82(15.53)$ & $-16.95^{*}(8.95)$ & $-4.98(14.29)$ \\
\hline Rural area & $-19.99(14.53)$ & $-0.74(13.81)$ & $-18.77(12.29)$ & $-5.58(16.42)$ \\
\hline Household has two dependent children & $37.28^{* * *}(11.97)$ & $1.27(25.10)$ & $22.21^{* *}(10.13)$ & $9.52(29.50)$ \\
\hline Household has three dependent children & $38.44^{* * *}(13.23)$ & $1.09(21.91)$ & $22.68^{* *}(11.19)$ & $9.45(29.44)$ \\
\hline Household has four or more dependent children & $69.50^{* * *}(15.81)$ & $6.31(100.92)$ & $46.38^{* * * *}(13.38)$ & $32.71(76.95)$ \\
\hline
\end{tabular}


Table 8: $\quad$ Women, Two Weekend Days

\begin{tabular}{|c|c|c|c|c|}
\hline \multirow{3}{*}{ Dependent Variables } & \multicolumn{4}{|c|}{ Window lengths } \\
\hline & \multicolumn{2}{|c|}{ 24-hour } & \multicolumn{2}{|c|}{ 48-hour } \\
\hline & OLS & Tobit & OLS & Tobit \\
\hline \multicolumn{5}{|l|}{ Selected Person-level Explanatory Variables } \\
\hline Single & $-49.21^{*}(28.54)$ & $-51.66^{* * *}(19.92)$ & $-31.94(24.79)$ & $-34.42^{*}(20.44)$ \\
\hline Speaks language other than English at home & $-15.05(22.63)$ & $-17.22(16.87)$ & $-3.96(19.66)$ & $-10.95(17.14)$ \\
\hline Bachelors degree or higher & $66.97^{* *}(27.08)$ & $69.81^{* * *}(27.18)$ & $70.64^{* * *}(23.52)$ & $73.63^{* * *}(24.85)$ \\
\hline \multicolumn{5}{|l|}{ Selected Household-level Explanatory Variables } \\
\hline Indicator for other adults (age 15+) in the household & $-89.93^{* * *}(29.46)$ & $-77.50^{* * *}(20.36)$ & $-80.75^{* * *}(25.59)$ & $-68.54^{* * *}(19.89)$ \\
\hline Age of youngest child in household is 2 to 4 years & $-85.91^{* * *}(18.63)$ & $-68.06^{* * *}(17.88)$ & $-88.54^{* * *}(16.18)$ & $-77.76^{* * *}(15.67)$ \\
\hline Age of youngest child in household is 5 to 9 years & $-134.19^{* * *}(19.12)$ & $-94.06^{* * *}(17.90)$ & $-120.37^{* * * *}(16.61)$ & $-93.53^{* * *}(16.01)$ \\
\hline Age of youngest child in household is greater than 9 years & $-156.66^{* * *}(21.11)$ & $-121.25^{* * *}(17.09)$ & $-142.31^{* * *}(18.33)$ & $-116.81^{* * *}(15.92)$ \\
\hline Non-metropolitan urban area & $-6.54(13.41)$ & $-3.53(10.70)$ & $-7.31(11.65)$ & $-2.41(10.22)$ \\
\hline Rural area & $-9.91(19.02)$ & $1.43(15.40)$ & $-6.99(16.53)$ & $-4.94(14.30)$ \\
\hline Household has two dependent children & $-6.98(14.75)$ & $-2.81(12.07)$ & $2.26(12.82)$ & $3.07(11.20)$ \\
\hline Household has three dependent children & $-3.69(17.54)$ & $9.47(14.81)$ & $6.55(15.24)$ & $15.24(13.85)$ \\
\hline Household has four or more dependent children & $-21.63(20.97)$ & $-23.51(15.68)$ & $-5.24(18.22)$ & $-9.10(15.74)$ \\
\hline
\end{tabular}

We compared models across diary length using F-tests for the linear models and likelihood ratio tests for the censored Tobit models. The results of the F-tests for the linear models indicate that there is no difference between the 24-hour and 48-hour estimates in most cases. The one exception involves a marginally significant improvement in the results for women in the two-weekend-day sample when using 48 hours rather than 24 hours of information. The results of the likelihood ratio tests for the Tobit models indicate that the estimates improve when using the 48-hour window instead of the 24-hour window for both men and women when the 48-hour window includes both day types. Thus it is important to capture both types of days for the same person. Because we found this difference only for the Tobit models, it also suggests that estimates from such models are more sensitive to the types of diary day(s) available than linear models.

For the both-day-type sample (Tables 3 and 4), we find virtually no difference in the qualitative results of our models regardless of whether we use a linear or censored model, for either gender. Magnitudes, however, generally shrink slightly for both models when we decrease the measurement error in the dependent variable by expanding the window length. There are also some sizable differences between OLS- and Tobit-estimated effects and, in general, Tobit estimates are smaller than OLS estimates, particularly for the household-level variables. Despite these differences, the qualitative conclusions are similar whether we use two days or one, or fit linear or censored models.

Turning to Tables 5 and 6 that contain results for our two-weekday samples, we again see that the choice between OLS and Tobit makes little difference to the qualitative conclusions we draw regarding the determinants of women's child care time and that women's Tobit marginal effects are again slightly smaller, in general, than the OLS-estimated effects. However, the results are different for men. For men, the Tobit model fit to the 24-hour diary window results in insignificant marginal effects across the board. When we expand the window to 48 hours, some marginal effects become significant in a pattern that is similar to that for the OLS 
effects. However, just as for women, the Tobit marginal effects for men are generally smaller than the OLS effects.

Finally, Tables 7 and 8 present results using our two-weekend-day samples. Similar patterns to those in previous tables hold for women, but for men, the Tobit models do not result in significant estimates using either the 24-hour or the longer 48-hour time diary window. Once again, OLS-estimated effects are qualitatively similar across window length for both genders.

\section{Discussion}

Even though there is measurement error in a 24-hour time diary due to the presence of false zeros, there is also real non-participation in child care as a primary activity if the analyst considers 48 hours as the time period over which an individual optimizes. Thus, an argument can be made that some censoring is real and should be addressed via the estimation of a censored Tobit model, despite the fact that OLS estimation of a linear model yields significant estimates for every gender-day-type combination we use and hence is attractive empirically. We find slight differences in magnitudes when comparing OLS and Tobit marginal effects, but for most of our models, qualitative results are similar regardless of window length or estimation method. However, importantly, the Tobit estimates appear to be more sensitive to window length than the OLS estimates, and for men in particular, Tobit models do not yield significant results when estimated only using weekend days, regardless of window length. We conjecture that this is due to the increased heterogeneity and lumpiness across day types of men's time allocation to child care compared to women's. We conclude that while analysts may prefer Tobit on theoretical grounds, they should be cautious when interpreting Tobit marginal effects based on a single diary day or for activities for which time is allocated in a lumpy and heterogeneous fashion.

\section{References}

Floro, M.S. and M. Miles (2003), Time Use, Work and Overlapping Activities: Evidence from Australia, in Cambridge Journal of Economics, Vol. 27, No. 6, 881-904.

Gershuny, J. and M. Egerton (2007), Time and Participation: Modelling Unpaid Work using Time Diary Data A Framework for investigating the suitability of OLS for modelling diary-derived time-use dependent variables, Unpublished manuscript.

Greene, W.H. (1997), Econometric Analysis, Third Edition, New Jersey, Prentice-Hall.

Kalenkoski, C.M. and G. Foster (2008), The Quality of Time Spent with Children in Australian Households, in Review of Economics of the Household, Vol. 6, No. 3, 243-266.

Kalenkoski, C.M., Ribar, D.C., and L.S. Stratton (2005), Parental Child Care in Single Parent, Cohabiting, and Married Couple Families: Time Diary Evidence from the United Kingdom, in American Economic Review (Papers and Proceedings), Vol. 95, No. 2, 194-198.

Kalenkoski, C.M., Ribar, D.C., and L.S. Stratton (2007), The Effect of Family Structure on Parents' Child Care Time in the United States and the United Kingdom, in Review of Economics of the Household, Vol. 5, No. 4, 353-384. 


\section{Foster/Kalenkoski}

Kalenkoski, C.M., Ribar, D.C., and L.S. Stratton (2009), The Influence of Wages on Parents' Allocations of Time to Child Care and Market Work in the United Kingdom, in Journal of Population Economics, Vol. 22, No.2, 399-419.

Kimmel, J. and Rachel Connelly (2007), Mothers' Time Choices: Caregiving, Leisure, Home Production, and Paid Work, Journal of Human Resources, Vol. 42, No. 3, 643-681.

Stewart, J. (2009), Tobit or Not Tobit? IZA Discussion Paper No. 4588. 